\title{
Leading article
}

\section{Regulation of metal absorption in the gastrointestinal tract}

'Chemical composition determines physical structure. Physical structure determines physiological function.' $\boldsymbol{A}$ F Hofmann

In this century industrial changes have greatly increased our exposure to many metals but fortunately their intestinal absorption is highly selective. For example, only $0 \cdot 1 \%$ of the toxic metal aluminium is absorbed, ${ }^{1}$ whereas the group 1A elements such as sodium and potassium are nearly completely absorbed. ${ }^{23}$

The principles underlying the absorption of metals are relevant to many nutrients and drugs, but the specific factors that regulate the absorption of metals are determined by their atomic structure, because this determines the chemical properties of the element and therefore its physiological function and metabolism. Hence, we start with simplified in vitro models and develop them to describe the complex mechanisms that determine selectivity of metal absorption from the gastrointestinal tract.

\section{Solubility}

The solubility of most metals changes with $\mathrm{pH}$ and because there is typically a decrease in proton concentration of about four orders of magnitude within the lumen from the stomach to the proximal small bowel, $\mathrm{pH}$ has been a major focus of most simple in vitro studies in which the chemical speciation of metals has been studied under 'simulated' gastrointestinal conditions. Gastric acid favours the dissolution of many metals, ${ }^{4}$ although notably not bismuth, which is largely insoluble in dilute hydrochloric acid due to the formation of precipitated bismuth oxychloride. ${ }^{5}$ Many of the acid soluble cations (aluminium, copper, iron, zinc, etc) are least soluble at the neutral $\mathrm{pH}$ encountered in the small bowel. This is due to their 'hydrolytic' nature, which means that water molecules, coordinated around the metal ion, lose protons at around neutral $\mathrm{pH}$ to form a hydroxy-metal species. Such a process is consistent with Le Chatelier's principle, that, as an acidic solution is neutralised and hence protons are lost, so further protons are released by the water molecules coordinated around the metal in an attempt to maintain the equilibrium. Ultimately, the hydroxy-metal species polymerises, liberating further protons, and if a neutral $\mathrm{pH}$ is maintained a turbid white precipitate of metal-hydroxide is rapidly observed. This process may be summarised in the two equations below:

$$
\mathrm{M}^{\mathrm{m}+}\left(\mathrm{H}_{2} \mathrm{O}\right)_{\mathrm{n}} \stackrel{\left(-\mathrm{mH}^{+}\right)}{\longrightarrow} \mathrm{M}^{\mathrm{m}+}\left(\mathrm{H}_{2} \mathrm{O}\right)_{\mathrm{n}-\mathrm{m}}\left(\mathrm{OH}^{-}\right)_{\mathrm{m}}
$$

equation (I)

$\mathrm{xM}^{\mathrm{m}+}\left(\mathrm{H}_{2} \mathrm{O}\right)_{\mathrm{n}-\mathrm{m}}\left(\mathrm{OH}^{-}\right)_{\mathrm{m}} \stackrel{\left(-\mathrm{yH}_{2} \mathrm{O}\right)}{\longrightarrow}$ Hydroxy-metal polymer ('precipitate') equation (II)

Although it has been suggested that such precipitation explains the poor absorption of elements such as aluminium, ${ }^{67}$ this does not explain the much better absorption of, say, copper or zinc. Indeed, this precipitation theory ignores endogenous secretions that considerably modify the chemistry of these metals in the gastrointestinal tract and, while the hydrolytic nature of a metal is one factor in determining its absorption, gross metal-hydroxide precipitates do not occur in the gastrointestinal lumen.

\section{Endogenous secretions}

Bile, gastric, and pancreatic juices and succus entericus are all secreted into the gastrointestinal lumen. Each of these contain a complex mixture of compounds, many of which will influence the chemistry of ingested metal ions. Using high resolution nuclear magnetic resonance spectroscopy, we have identified many potential low molecular weight 'weak' ligands within these secretions at $\mathrm{mM}$ concentrations. ${ }^{8}$ They typically include short chain organic acids, such as acetate and lactate, and many aminoacids such as glycine, histidine, and phenylalanine.

A ligand may be considered weak if it has some affinity for a metal, but in a competitive situation at equilibrium the two do not significantly bind. For example, at neutral $\mathrm{pH}$, a weak ligand would not effectively compete with hydroxide (from water) to prevent hydroxy-polymerisation of hydrolytic metals (equations I and II above), but it could slow the rate of this polymerisation and considerably reduce the particle size of the final species. We have shown this during the formation of aluminium hydroxide particles in the presence of $50 \mathrm{mM}$ bicarbonate. ${ }^{89}$ Bicarbonate is sufficiently small and mobile to interfere, at least transiently, with the hydrolysis (equation I, above) and the subsequent condensation reaction that is required for

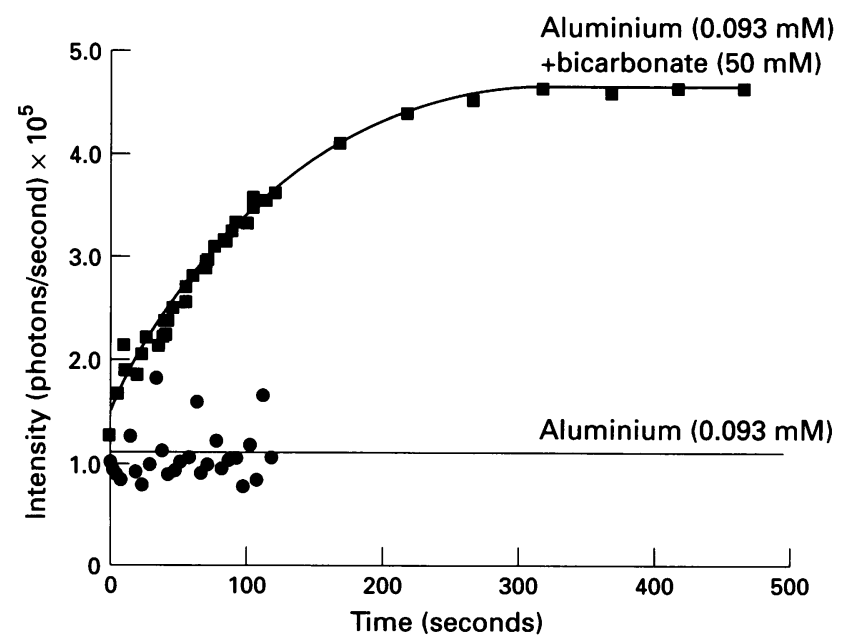

Figure 1: $A$ solution of aluminium chloride at acidic $p H$ was precipitated, in the presence and absence of bicarbonate, by adjusting the $p H$ to neutral (titrated and $\mathrm{pH}$ metered). Intensity of light scattering by the resultant suspensions showed that the presence of bicarbonate yielded more and smaller particles (that is, increased intensity) that took longer to form. 
polymerisation to proceed (Fig 1). Indeed, the concentration and heterogeneity of the low molecular weight compounds that are secreted into the gastrointestinal lumen should be sufficient to slow the rate of hydroxypolymerisation of any ingested hydrolytic metal. Precipitation would still occur in vitro, but in vivo, the situation is more complex. Low molecular weight 'strong' ligands that will significantly bind with metals in competitive situations, such as citrate and malate, are found endogenously in the gastrointestinal tract, ${ }^{10}$ but only at low concentrations and so will also compete with hydrolysis only to a degree comparable to that of the weak ligands found at their much higher concentrations. Likewise, potentially strong ligands of high molecular weight, including the proteins albumin, lactoferrin, and transferrin, which are largely exsorbed in the succus entericus, are probably partly degraded in the bowel lumen and quantitatively would not significantly bind metal ions. However, another secretion that will actually prevent hydroxy-metal precipitation is mucus glycoprotein (mucin). This is continuously secreted in large amounts and binds to metals comparatively strongly, greatly influencing their absorption.

\section{Luminal mucins}

Mucins are large glycosylated proteins that form both soluble and insoluble phases within the gastrointestinal tract. ${ }^{11}$ The insoluble phase is chiefly the mucosally adherent gelatinous layer termed mucus, although insoluble mucin strands are also found throughout the lumen. The soluble phase includes dissolved and partially degraded mucins and, for example, is present in gastric juice at $0.2 \mathrm{~g} / 1 .^{12}$ Mucins have large capacities for the binding of metal ions, although trivalent metals are bound more strongly than those that are divalent and monovalent metals are only ionically (that is, poorly) bound. ${ }^{13}$ Our recent in vivo work with aluminium, which is a good example of an hydrolytic metal, has shown that the element almost exclusively binds to mucins throughout its transit of the small intestinal lumen ${ }^{14}$ (Fig 2). The precise mechanism of this interaction is unclear, but initially probably proceeds through the terminal sialic acid residues of luminal mucins. ${ }^{15}$ These could either bind at multiple sites the hydroxy-metal species as they polymerise, or, particularly for the non-hydrolytic metals (for example, $\mathrm{Ca}^{2+}$ or $\mathrm{Mg}^{2+}$ at physiological $\mathrm{pH}$ ), interact directly, but more weakly, with the metal ion. Indeed, the luminal iron binding glycoprotein, gastroferrin, which was much investigated $20-30$ years ago, is almost certainly made up of partly degraded soluble mucins from the stomach and maintains high affinity for metals and metal-ion hydroxy colloids at intestinal $\mathrm{pH} .{ }^{16}{ }^{17}$

Gross precipitation of hydrolytic metals is therefore prevented and the polyhydroxy-metal species remains in an easily dissociable form available for uptake. Thus essential hydrolytic elements, such as copper, iron, manganese, and zinc, are effectively absorbed. This stabilisation of polyhydroxy-metal species has been well studied for the hydroxy-ferric-fructose system, in which an extended fructose network maintains iron in solution and prevents precipitation. ${ }^{18}$ The resultant hydroxy-ferric-fructose complex is, in comparison to other ferric compounds, easily able at neutral pHs to donate its iron to stronger binding sites. It is probable that soluble mucins similarly stabilise the hydroxy metal polymers as they start to form in the gastrointestinal lumen.

Although not as available or mobile as simple ions $\left(\mathrm{Na}^{+}\right.$, $\mathrm{Mg}^{2+}$, etc) the hydrolytic metals are nevertheless maintained in the gastrointestinal lumen in a form that is considerably more available than the metal-hydroxide
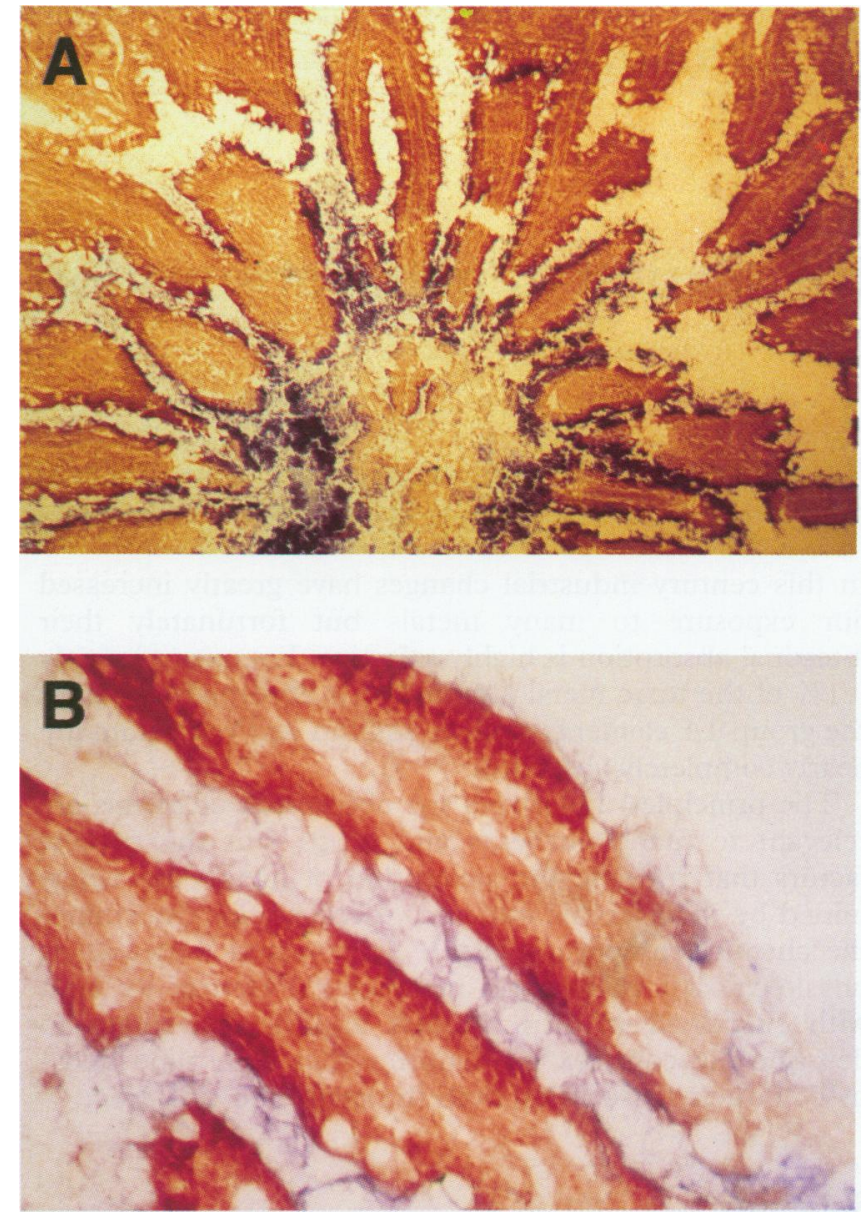

Figure 2: (A) Solochrome azurine stain of a section of proximal small bowel of rat (shown red) gavaged with aluminium (shown blue). Aluminium is colocalised with mucus, both at the mucosal surface and in the lumen. The areas of aluminium that appear particulate are not, under high power, discrete precipitates but dense areas of aluminium, probably as metal-hydroxy colloid, interacting with luminal mucins (original magnification $\times 100$ ). (B) Villi (shown red) with mucosally adherent mucus that has bound aluminium from the intestinal lumen (shown blue) (original magnification $\times 400$ ).

precipitates. A selective process is then required at the mucosal surface to allow the absorption of essential metals and the rejection of toxic metals. The first major regulatory factor is the mucosally adherent mucus layer.

\section{Mucus}

Mucus is a gelatinous layer that is both a defence barrier and transport medium at the mucosal surface, and is composed of a network of mucins with occasional nonmucin components including polysaccharides, lipid, secretory IgA, and lactoferrin. ${ }^{19}$ Mucus secretory cells are particularly numerous in the stomach where a thick layer of mucus (mean $180 \mu \mathrm{m}$ in humans ${ }^{20}$ ) protects against autodigestion, and, indeed, in the antrum, the pyloric glands are composed almost exclusively of mucus secretory cells. ${ }^{21}$ In the small bowel the mucus layer is thinner ${ }^{22}$ (mean $50 \mu \mathrm{m}$ in humans) and produced mainly by the goblet cells, ${ }^{23}$ although secretions from the enterocytes and from duodenal Brunner's glands ${ }^{24}$ may also contribute to this structure. In mucus both the greater concentration of adherent mucins relative to luminal mucins and the increased spacial proximity of the sialic acid binding groups will favour the extraction of metals from the contents of the intestinal lumen into the mucus layer (Fig 2). This mucus layer, however, is continually shed and replaced by further secretion. Hence the ability of metal ions to permeate this layer and reach the mucosa will 
depend on their mobility through mucus, which in turn is governed inversely by their strength of binding to the mucus gel $\left(\mathrm{M}^{3+}>\mathrm{M}^{2+}>\mathrm{M}^{+}\right)$and directly by their rates of ligand exchange (typically $\mathrm{M}^{+}>\mathrm{M}^{2+}>\mathrm{M}^{3+}$ ). Hence the general rule is that the rate of absorption of metals is in the order $\mathrm{M}^{+}>\mathrm{M}^{2+}>\mathrm{M}^{3+}$, exemplified by poor absorption of $\mathrm{Fe}^{3+}$ compared with that of $\mathrm{Fe}^{2+}$.

However, the bowel is more selective than this and before systemic absorption intramucosal factors further regulate absorption of metals.

\section{Mucosal factors}

Absorption may occur either trans or paracellularly. The paracellular pathway ${ }^{25}$ is inefficient (typically $<1 \%$ of an ingested dose), although certain 'penetration enhancers' ${ }^{26}$ that relax the junctions between enterocytes may increase permeability either by inducing cytoskeletal contraction, such as with glucose ${ }^{27}$ and some amino acids, ${ }^{26}$ or by lowering the concentration of intercellular free calcium, such as with EDTA and citric acid. ${ }^{28}$ Thus in the small bowel the pore size of the tight junction may be increased from $0.5-1 \mathrm{~nm}$ to $5 \mathrm{~nm}^{29}$ and there is evidence that the junctions surrounding goblet cells are more permeable than those surrounding enterocytes. ${ }^{30}$ In the stomach still larger complexes may be translocated paracellularly ${ }^{31}$ but this is unlikely to be of any quantitative importance. ${ }^{32}$

In considering the mechanisms of absorption of different metals, transport as a function of the metal-ion or of the metal-species must be distinguished. For example, endocytosis of haem iron or metal containing particles is related to the properties of the haem complex or particulates rather than to the properties of the constituent elements. Hence, although intestinal paracellular 'leakage' is the dominant means of mucosal permeation for the poorly absorbed polyvalent metals, ${ }^{33}$ the absorption of mono- or di-valent metals is mainly by the more specific transcellular route. This is traditionally considered as either facilitated transmembrane assimilation or passive transmembrane diffusion.

It is commonly considered that there are membrane 'shuttles' to transport metals actively from the lumen into the enterocyte although evidence for these remains elusive. Recently a $230-240 \mathrm{kDa}$ membrane integrin has been noted to associate with ferric iron ${ }^{34}$ but further data are lacking and the significance of this interaction remains unclear. Moreover, membrane proteins are not required for transport because chelating substances within the enterocyte would create a gradient facilitating the transport of metals from the lumen. Intracellular ferritin and transferrin have been proposed as such mucosal agents for iron, ${ }^{35}{ }^{36}$ although intracellular ferritin is chiefly produced in response to iron, while a transferrinanaemia causes iron overload rather than depletion. ${ }^{37}$ More recently, a $56 \mathrm{kDa}$ protein 'mobilferrin' has been proposed as an iron binding protein within the enterocyte cytosol, ${ }^{38}$ but it is unlikely that it can compete for iron in the presence of the much higher in vivo concentrations of free calcium. It is plausible that there is no facilitated transport for $\mathrm{M}^{3+}$ to protect against toxicity (for example, $\mathrm{Al}^{3+}$ ) and that prior reduction of $\mathrm{Fe}^{3+}$ is required for efficient transport; indeed such a 'ferrireductase' enzyme has recently been characterised and partially purified from the membranes of human duodenal microvilli. ${ }^{39}$ This would reduce the small amount of $\mathrm{Fe}^{3+}$, that traverses the mucus, to $\mathrm{Fe}^{2+}$, facilitating the uptake of iron.

Metallothioneins are rapidly inducible intracellular $\mathrm{M}^{2+}$ chelating agents, ${ }^{40}$ while a further cysteine rich intestinal protein has been recently investigated for its role in zinc absorption. ${ }^{41}$ These, and undoubtedly many other $\mathrm{M}^{2+}$ binding agents, form a complex network of metal-ligand interactions with the different cations that not only permits the assimilation of $\mathrm{M}^{2+}$ from the lumen, but also controls their systemic release. Thus, although cadmium and zinc are both comparatively well absorbed into the enterocyte, cadmium binds strongly to metallothionein and is therefore largely not released systemically, while zinc is less irreversibly bound and can more efficiently shuttle into the blood. ${ }^{42}$

\section{Conclusion}

In conclusion, the absorption of metals is determined by: (a) the degree of solubilised metal entering the small bowel, (b) the extent of hydrolysis at $\mathrm{pH} \mathrm{5-7,} \mathrm{(c)} \mathrm{the} \mathrm{rate}$ of transport through the mucus layer, and (d) mucosal control. The great differences in the absorption of metals can largely be explained on the basis of their chemical properties, namely of $\mathrm{Na}^{+}, \mathrm{K}^{+}, \mathrm{Li}^{+}$(non-hydrolytic, very weakly bound, kinetically active) $>\mathrm{Ca}^{2+}, \mathrm{Mg}^{2+}$ (nonhydrolytic at intestinal $\mathrm{pH}$, relatively weakly bound, kinetically active) $>\mathrm{Zn}^{2+}, \mathrm{Cu}^{2+}$ (hydrolytic, relatively strongly bound, kinetically active) $>\mathrm{Cd}^{2+}, \mathrm{Hg}^{2+}$ (hydrolytic, relatively strongly bound, kinetically active but mucosally controlled) $\mathrm{Fe}^{3+}$ (hydrolytic, strongly bound, kinetically less active), $>\mathrm{Al}^{3+}$ (hydrolytic, strongly bound, kinetically slow).

$M$ W WHITEHEAD R P H THOMPSON

Gastrointestinal Laboratory, J J POWELL

The Rayne Institute, St Thomas's Hospital, London SE $17 E H$

1 Powell J, Thompson RPH. The chemistry of aluminium in the gastrointestinal lumen and its uptake and absorption. Proc Nutr Soc 1993; S2: 241-53.

2 Hazell T. Minerals in Foods: dietary sources, chemical forms, interaction, bioavailability. World Rev Nutr Diet 1985; 46: 1-123.

3 Luisier PA, Shutz P, Dick P. The pharmacokinetics of lithium in normal humans: expected and unexpected observations in view of kinetic principles. Pharmacopsychiatry 1987; 20: 232-4.

4 Lote CJ, Saunders $H$. Aluminium: gastrointestinal absorption and renal excretion. Clin Sci 1991; 81: 289-95.

5 Lee SP. A potential mechanism of action of colloidal bismuth subcitrate: diffusion barrier of hydrochloric acid. Scand $\mathcal{F}$ Gastroenterol 1982; 17: $17-21$

6 Williams DR. Analytical and computer simulation studies of a colloida bismuth citrate system used as an ulcer treatment. F Inorg $\mathrm{Nucl}$ Chem 1992; 39: 711-4.

7 Stewart WK. Aluminium toxicity in individuals with chronic renal disease. In: Massey RC, Taylor D, eds. Aluminium in good and the environment. London, Royal Society of Chemistry, 1989: 7-19.

8 Powell JJ. Aluminium in the gastrointestinal tract. PhD thesis. London: London University, 1994.

9 Powell JJ, Taylor P, Thompson RPH. Metal ligand interactions under physiological conditions. F Inorg Chem 1993; 51: B133.

10 Piper DW, Fenton BH, Goodman LR. Lactic, pyruvic, citric, and uric acid and urea content of human gastric juice. Gastroenterology 1967; 53: 42-8.

11 Rhodes JM. Colonic mucus and mucosal glycoproteins: the key to colitis and cancer. Gut 1989; 30: 1660-6.

2 Lambert R, André C. Sulfated muco-substances and gastric diseases. Digestion 1972; 5: 116-20.

13 Crowther RS, Marriott C. Counter-ion binding to mucus glycoproteins. F Pharm Pharmacol 1984; 36: 216.

14 Whitehead MW, Powell JJ, Thompson RPH. The gut mucus layer regulates metal absorption? Gut 1995; 36: A48.

15 Crowther RS. Cation induced changes in the biophysical properties of mucus glycoproteins. PhD thesis. London: London University, 1982

glycoproteins. PhD thesis. London: London University, 1982.
16 Davis PS, Multani JS, Cepeeneek CP, Saltman P. Isolation of gastroferrin from human gastric juice. Biochem Biophys Res Commun 1969; 37: 532-7.

17 Rudzki Z, Baker RJ, Deller DJ. The iron-binding glycoprotein of human gastric juice II nature of the interaction of the glycoprotein with iron.

18 Bates G. Complex formation, polymerization, and autoreduction in the ferric fructose system. Bioinorg Chem 1973; 2: 311-27.

19 Clamp JR, Creeth, JM. Some non-mucin components of mucus and their possible biological roles. In: Nugent J, O'Connor $M$, eds. Mucus and mucosa (Ciba Foundation Symposium 109). London: Pitman, 1987 121-36

20 Hunter AC, Allen A, Garner A. Studies on mucus biosynthesis in the gastrointestinal tract. In: Chantler E, Ratcliffe NA, eds. Mucus and related topics (Symposia of the society for experimental biology No XLIII) 1986: 27-30.

21 Takeoka Y, Kataoka K. Histogenesis of the mouse pyloric mucosa with special reference to the development of surface mucus cells and 
pylorocytes and the formation of the generative zone. Arch Histol fpn 1986; 49: 519-34.

22 Powell J, Whitehead MW, Lee S, Thompson RPH. Mechanisms of gastrointestinal absorption and dietary minerals and the influence of beverage ingestion. Food Chem 1994; 51: 381-8.

23 Specian RD, Neutra $M$. Mechanism of rapid mucus secretion in goblet cells stimulated by acetyl choline. F Cell Biol 1980; 85: 626-40.

24 Kirkegaard P, Lundbert JM, Seier Poulsen S, Skov Olsen P, Fahrenkrug J, Hokfelt T. et al. Vasoactive intestinal polypeptidergic nerves and Brunners gland secretion in the rat. Gastroenterology 1981; 81: 872-8.

25 Madara JL. Pathobiology of the intestinal epithelial barrier. Am $\mathcal{f}$ Pathol 1990; 137: 1273-81.

26 Lee VHL, Yamoto A, Kompella UB. Mucosal penetration enhancers for facilitation of peptide and protein drug absorption. Crit Rev Ther Drug

27 Madara JP, Pappenheimer JR. Structural basis for physiological regulation of paracellular pathways in intestinal epithelia. F Memb Biol 1987; 100: 149-64.

28 Martinez-Paloma A, Meza I, Beaty G, Cereijido M. Experimental modulation of occluding junctions in a cultured transporting epithelium. f Cell Biol 1980; 87: 736-45.

29 Sanderson IR, Walker AW. Uptake and transport of macromolecules by the intestine: possible role in clinical disorders (an update). Gastroenterology 1993; 104: 622-39.

30 Froment DM, Molitoris BA, Buddington B, Miller N, Alfrey AC. Site and mechanism of enhanced gastrointestinal absorption of aluminium by citrate. Kidney Int 1989; 36: 978-81.
31 Fraser AG, Lewin JP, Pounder RE. Gastric persorption of bismuth from ranitidine bismuth citrate. Aliment Pharmacol Therap 1995; 9: 447-50.

32 Menge H, Gregor M, Brosius B, Hopert R, Lang A. Pharmacology of bismuth. Eur $\mathscr{f}$ Gastroenterol Hepatol 1992; 4: 241-7.

33 Provan SD, Yokel RA. Aluminium uptake by the in situ rat gut sac preparation. F Pharmacol Exp Ther 1988; 245: 928-31.

34 Conrad ME, Umbreit JA. A concise review: Iron absorption- the mucinmobilferrin-integrin pathway. A competitive pathway for metal absorption. Am f Hematol 1993; 42: 67-73.

35 Granick S. Protein apoferritin and ferritin in iron feeding and absorption. ¥ Biol Chem 1946; 164: 737-46.

36 Huebers HS, Huebers E, Csiba E, Rummel W, Finch CA. The significance of transferrin for intestinal iron absorption. Blood 1983; 61: 283-90.

37 Goya N, Miyyazaki S, Kodate S, Ushio B. A family of congenital atransferrinemia. Blood 1972; 40: 239-45.

38 Conrad ME, Umbreit JA, Moore EG, Peterson RDA, Jones MB. A newly identified iron binding protein in duodenal mucosa of rats. $\mathcal{F}$ Biol Chem 1990; 265: 5273-9.

39 Riedal H-D, Remus AJ, Fitscher BA, Stremmel W. Characterization and partial purification of a ferrireductase from human duodenal microvillus membranes. Biochem f 1995; 309: 745-8.

40 Brenner I. Nutritional and physiological significance of metallothionein. In: Methods in enzymology. 205. Academic Press, 1991: 25-35.

41 Hempe JM, Cousins RJ. Cysteine-rich intestinal protein binds zinc during transmucosal zinc transport. Proc Natl Acad Sci USA 1991; 88: 9671-4.

42 Krazter FH, Vohra P. Chelates in nutrition. Boca Raton, CRC Press, 1986. 